\title{
IN-TE $\mathrm{H}_{\lrcorner}$Six Sigma Driven Enterprise Model Transformation
}

\author{
Raymond Vella1, Sekhar Chattopadhyay² and John P.T. Mo² \\ ${ }^{1}$ Ford Motor Company Australia \\ 2RMIT University; Australia \\ Corresponding author E-mail: thanksjohn.mo@rmit.edu.au
}

Abstract: Enterprise architecture methods provide a structured system to understand enterprise activities. However, existing enterprise modelling methodologies take static views of the enterprise and do not naturally lead to a path of improvement during enterprise model transformation. This paper discusses the need for a methodology to facilitate changes for improvement in an enterprise. The six sigma methodology is proposed as the tool to facilitate progressive and continual Enterprise Model Transformation to allow businesses to adapt to meet increased customer expectation and global competition. An alignment of six sigma with phases of GERAM life cycle is described with inclusion of Critical-To-Satisfaction (CTS) requirements. The synergies of combining the two methodologies are presented in an effort to provide a more culturally embedded framework for Enterprise Model Transformation that builds on the success of six sigma.

Keywords: Enterprise transformation, enterprise model, six sigma, model lifecycle, change management

\section{Introduction}

The volatility of current business environment requires companies to adapt to new processes and systems to satisfy customer requirements as well as remaining competitive (Rho et al, 2001). Business enterprise is inherently a complex entity. There are many risks involved in the changes that an enterprise needs to go through in order to transform itself to a more competitive form (Beasley et al, 2005). Typical risks include collaboration, confidentiality, intellectual property, transfer of goods, conflicts, opportunity loss, product liability and others. Inappropriate actions can be taken if the information is out of date (Kutsch \& Hall, 2005) or the employee performance can be seriously affected (Lin \& Wei, 2006). Kwon et al (2007) reported that those enterprises going through significant organisational change and downsizing of IT function was not simply reducing the workforce in the IT department. It also eliminated communication and information-processing conduits necessary for effective communication and coordination.

The uncertainty in business environment presents many research opportunities implementing engineering changes in enterprises. Rouse (2005a) found that value deficiencies and work processes defined the problem of Enterprise Transformation and that many fundamental changes addressed value from the perspective of the customer. Rouse also discussed how the problem solving and decision making ability of management could influence the outcomes of transformation, but did not elaborate on specific tools to guide the transformation. Yin and Shanley (2008) proposed a three dimensions model that could assist decision makers to merge or form alliances. Oberg et al (2007) presented the concept of "network pictures" as the modelling framework to illustrate and analyse changes in managerial sensemaking and networking activities following a enterprise change. They concluded that following a major enterprise transformation managers may need to adapt their previous network structure in a radical way.

The dynamics of enterprise change was analysed by Marino and Zabojnik (2006). In their analysis, if new firms can enter the market quickly, it is more likely that enterprise change is motivated by efficiency improvement as opposed to increased market power. Thus, there is less reason to challenge the change as it comes internally. However, many enterprises that have problems making changes generally suffer from human or organisational resistance (Buhman et al, 2005; Corbett, 2007). It is clear from these studies that issues on enterprise change should be dealt with in a systematic fashion, supported by a methodology that assists the whole of enterprise to transform.

Enterprise modelling is best used to analyse the business in both manufacturing and service sectors in terms of complexities and context. Enterprise reference architectures provide a structure to understand enterprise activities, for example, promote planning, reduce risk, implement new standard operating procedures and controls, rationalizing manufacturing facilities. Dewhurst et al (2002) identified five key design issues in constructing a generic enterprise model (GEM) when they attempted to "design" the enterprise model. Study of enterprise architecture requirements in the last decade has been focused on how enterprises can be designed and operated in relatively 
static, authoritative environment (Molina \& Medina, 2003; Mo et al, 2006). These enterprise engineering researches shared a common starting point, viz, stepwise, multi-dimensional enterprise modelling and design methodologies have been applied. The rationale to use enterprise engineering methodologies to guide these developments is to minimize the impact of uncertainty to enterprise performances as well as other associated processes (Ortiz et al, 1999).

There are limitations in the present enterprise modelling methodologies when applying them to modelling enterprise transformation. Current enterprise architectures are described tacitly with the assumption that the present state of enterprise does not change during the life cycle of the "enterprise engineering project" (Chen et al, 2008). In recent years, six sigma methodology (Jochem, 2006) has been embraced by many large and small corporations. The process focus of six sigma can benefit an enterprise by providing the means to develop a road map and initiate the required enterprise transformation that could become culturally more ingrained within the organisation. This paper examines the traditional approach of enterprise transformation by enterprise modelling design and explores how six sigma methodology can be used to facilitate a systematic enterprise modelling process providing a culturally embedded framework for enterprise transformation. We then propose a unified methodology incorporating 6 sigma in enterprise transformation and illustrate our proposed methodology by a case study.

\section{Enterprise transformation by architecture design}

To achieve enterprise transformation, architecture design approach uses the modelling formalism to create a baseline manufacturing enterprise model. The Generalised Enterprise Reference Architecture and Methodology (GERAM), which is an annex of ISO 15704, is a combined effort of an international task force (Williams et al, 1994). Based on a generic enterprise reference architecture, an enterprise model is captured as a business process engineering life cycle as shown in Figure 1.

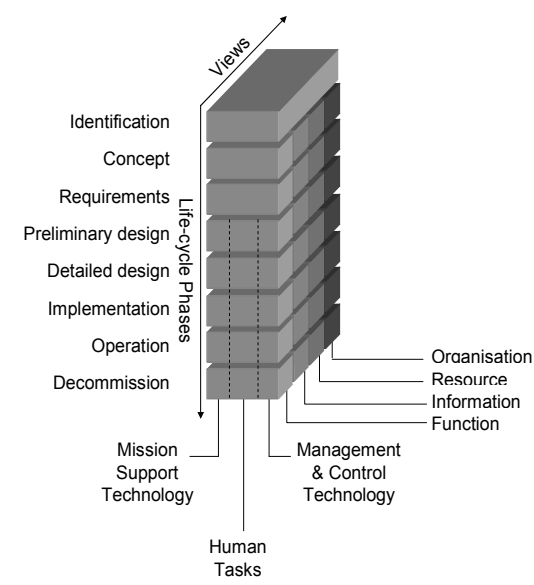

Fig. 1. The Generic Enterprise Reference Architecture

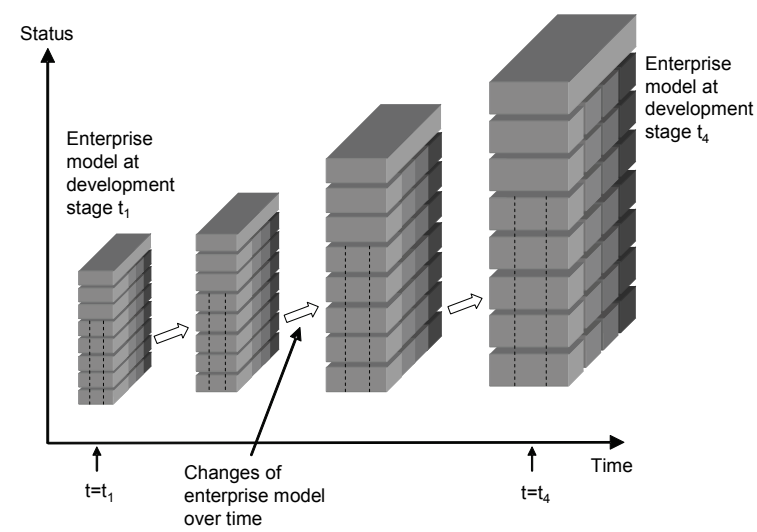

Fig. 2. Enterprise models at different phases of enterprise development

Details of the physical, information and human structures are recorded by modelling formalisms and tools. For example, manufacturing processes are recorded as material flow charts. Management practices are captured as work flow diagrams. IT system architectures are captured in software engineering tools, and so on. The methodology helps enterprise engineers to encapsulate functions and processes within the enterprise. In a typical enterprise improvement process, the current state of the enterprise is captured. The problems in the current state are identified. The generic methodology helps the business process engineer to visualise "snapshots" that lead to the identification of trends and changes in the enterprise architecture (Figure 2). Over time, enterprise models are changed progressively. The outcome is a new enterprise model that describes the desired state of the enterprise at a particular time. The enterprise model outlines the elements of an enterprise engineering process that leads to suitable executable reference architecture for an organisation to deliver the responsiveness. They are useful for enterprises where internal functions are clearly defined and changes to parts of the system can be controlled at system component boundaries. After the enterprise model is developed, simulation technique can be used to evaluate the anticipated effect of enterprise design decisions to system performance (Love \& Barton, 1996).

Traditional enterprise architectures are based on topdown approach. They emphasized on consistency throughout the organization and will involve all levels of employees. Normally, such a change is significant, since the organisation must have felt substantial pressure for a change that is more fundamental in nature. Changing the structure from current state to future state is often too long for dealing with the problem that the change intends to fix. The top-down approach also attracts inherent resistance to change from lower parts of the organisation. Furthermore, due to the fast changing business environment, the new model of the enterprise is a moving target. It takes a long time to progress from the current model to the newly designed enterprise architecture. When the changes are done half way through the 
transition, the enterprise designer is already under pressure to make further changes to the design under the new environment.

The enterprise architecture design approach focuses on designing the enterprise at different anticipated development stages using established enterprise design guiding principles (Uppington \& Bernus, 2003). The success of the new (future) enterprise depends on the "correctness" of the enterprise vision and well managed implementation. Although simulation technique can assist in clarifying the effect of some design factors, there are many other aspects of the enterprise that can be simulated or foreseen. The transformation is therefore risky and nonresponsive to external environment. There is no systematic study of how an enterprise should be transformed to achieve a less risky but progressive path. A new approach is required to assist enterprises not only in defining their enterprise model, but also on re-engineering their processes and structures in a predictable way.

\section{Change processes in six sigma}

Everything in a business can be viewed as a process. Thus, an enterprise can be viewed as a collection of integrated processes interweaved with the four views of the enterprise in Figure 1. A manufacturing enterprise receives an order, schedules the production, builds the product, delivers the product and receives payment. A service enterprise receives a customer request, schedules a customer appointment, delivers the service and receives payment. For process improvement, six sigma has been well recognised as a powerful tool and as an imperative for achieving and sustaining operational and service excellence. While the original focus of six sigma was on manufacturing, today it has been widely accepted in both service and transactional processes (Jiju, 2004).

Six sigma is a methodology for process improvement through reduced variability and the elimination of defects. Six sigma addresses system deficiencies using data to make decisions and formulating data driven solutions (Smith, 2001). The tool set is a collection of well known methods and techniques that is readily available. Intuition may be used to brainstorm, but all decisions are made using measurable data benchmarked against a set of Critical to Satisfaction (CTS) criteria, hence achieving measurable financial returns to the bottom line of an organisation.

Six sigma is structured as a sequence of processes. DMAIC and DMADV are two streams of processes dealing with specific changes in organisations. DMAIC methodology is used to improve existing products or processes that are not performing to target or not meeting customer expectation. DMADV is used when the process or product does not already exist and one is required or when an existing process can not be optimised. Both streams consist of five steps as shown in Table 1. Six sigma processes are best represented as a cyclic spiral continuous improvement methodology (Figure 2).

\begin{tabular}{|c|c|c|c|}
\hline \multicolumn{2}{|c|}{ DMAIC } & \multicolumn{2}{c|}{ DMADV } \\
\hline $\begin{array}{c}\text { Define the project } \\
\text { goals and customer } \\
\text { (internal and } \\
\text { external) CTS } \\
\text { deliverables }\end{array}$ & $\mathrm{D}$ & $\begin{array}{c}\text { Define the project goals } \\
\text { and customer (internal } \\
\text { and external) CTS } \\
\text { deliverables }\end{array}$ \\
\hline $\begin{array}{c}\text { Measure the } \\
\text { process CTS } \\
\text { deliverables to } \\
\text { determine current } \\
\text { performance using } \\
\text { verified } \\
\text { measurements }\end{array}$ & $\mathrm{M}$ & $\begin{array}{c}\text { Measure and determine } \\
\text { customer needs and } \\
\text { specifications }\end{array}$ \\
\hline $\mathrm{A}$ & $\begin{array}{c}\text { Analyze and } \\
\text { determine the root } \\
\text { cause(s) of the } \\
\text { defects }\end{array}$ & $\mathrm{A}$ & $\begin{array}{c}\text { Analyze and } \\
\text { characterize the process } \\
\text { options to meet the } \\
\text { customer needs }\end{array}$ \\
\hline I & $\begin{array}{c}\text { Improve the } \\
\text { process by } \\
\text { eliminating defects }\end{array}$ & $\mathrm{D}$ & $\begin{array}{c}\text { Design (detailed) and } \\
\text { optimize the process to } \\
\text { meet the customer } \\
\text { needs }\end{array}$ \\
\hline $\mathrm{C}$ & $\begin{array}{c}\text { Control future } \\
\text { process } \\
\text { performance }\end{array}$ & $\mathrm{V}$ & $\begin{array}{c}\text { Verify the design } \\
\text { performance and ability } \\
\text { to meet customer needs }\end{array}$ \\
\hline
\end{tabular}

Table 1. DMAIC and DMADV processes

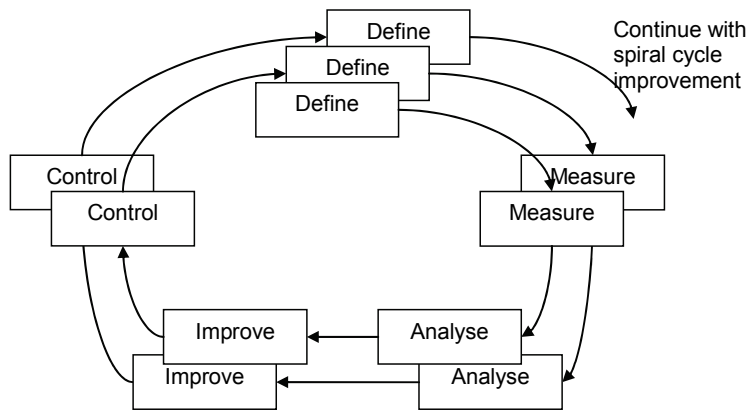

Fig. 2. Spiral six sigma improvement cycle

Six sigma is a tool that can create a new process or improve existing processes. Its main scope of application has been on making incremental changes to particular segments of an enterprise such as cultural change, customer focus, process elements and statistical methods of improvement (Goh, 2002). Extension of this scope to an enterprise wide improvement is not common. Goel and Chen (2008) discussed business process re-engineering in the context of integrating a global enterprise using six sigma. They focussed on defining metrics for process analysis and refinement with the appropriate identification and analysis of tools to make the process transformation. However, the total picture of how the processes are linked in the organisation and the selection of which process should be transformed was not discussed.

The overall objective of enterprise transformation is to improve or redefine the inadequate business processes with appropriate tools to ensure the process requirements are satisfied and that relevant targets such as cost, delivery, productivity, and so on are met (McGinnis, 2007). Török (2008) emphasises the need to begin with the 
strategic business level so as to identify and confront the serious business challenges. These cascade to the operational level which identifies potential six sigma projects where each project then contributes to the strategic business requirement and resulting enterprise transformation. Rouse (2005b) argued that research in enterprise transformation should include transformation methods and tools, which should represent, manipulate, optimize, and portray input, work, state, output and value for the past, present and future of the enterprise. Six sigma needs a clear, transparent integrated definition and description of the processes of the enterprise for it to optimise and operate successfully. Since enterprise architecture design approach uses tools and methods that take a bird's eye view of an enterprise, we propose a methodology combining the two approaches to maximise global improvement outcomes during enterprise model transformation.

\section{Transition between enterprise models}

Enterprise modelling provides a total enterprise view of processes, resources and technology. The level of integration, duplication or inefficiency in various processes may be derived through the development of the "As Is" enterprise model. Figure 3 shows a generic roadmap for enterprise model transformation. The existing business is represented with enterprise model $\mathrm{M}_{1}$ (the “AS IS" model). The forecast requirement is for an enterprise model as represented by enterprise model $\mathrm{Mn}$ (the "TO BE" model).

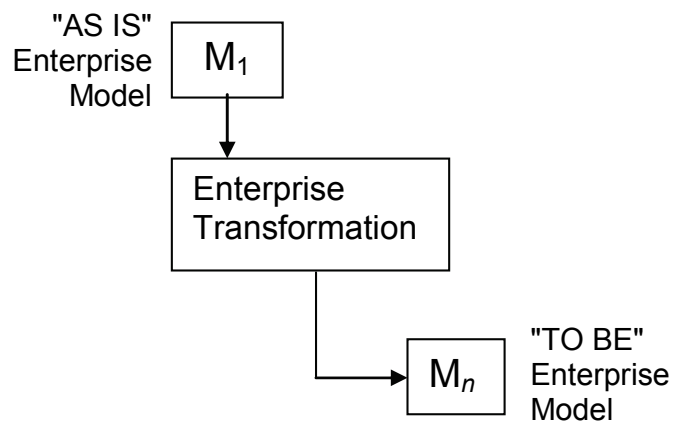

Fig. 3. Enterprise model transformations

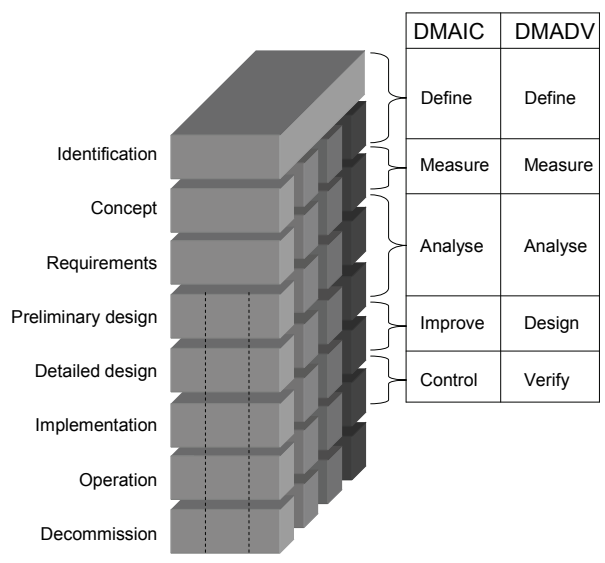

Fig. 4. GERAM alignment with six sigma
Enterprise modelling based transformation can be compared to six sigma methodology with the life cycle views of GERAM. Figure 4 shows how each of the five steps in six sigma would align with the phases of the enterprise lifecycle view.

In an "AS IS" enterprise model, the entire enterprise development is described as a snapshot of processes overlaying the four views. Irrespective of which phase a process has been developed, each process is explored to details as if it has been fully designed, implemented, operated and decommissioned. The enterprise is then regarded as fully described. If there is no change in identification and concept, which are often influenced by external parameters, the enterprise will progress through its lifecycle. Actual performance for each process may be benchmarked against targets thus highlighting processes with short fall performance. If the enterprise chooses, these processes can then be identified as candidates for six sigma projects, in which the processes are improved by focussing either on variability using the DMAIC process or redesigned using the DMADV process.

Six sigma has a narrow focus in its projects. Narrowness confines objectives in specific areas that maximise project support and ultimately aim at a successful conclusion. Transformation projects are selected by identifying what is critical to satisfaction (CTS) for the customer and what areas of the business are deficient. Six sigma methodology contains tools to identify measurable deliverables required for customer satisfaction and identifies areas, processes or inputs that influence these deliverables (Smith \& Fingar, 2003). Identifying and prioritizing these areas, processes or inputs against relevant criteria is one method that can be used to select six sigma projects that will lead to effective progressive enterprise transformation. The "AS IS" enterprise model can have varying levels of model maturity and granularity. Using six sigma, the business process engineer can focus on the relevant area and develop the necessary detail within the project scope. Thus, as shown in Figure 6, a six sigma project will take the "AS IS" enterprise model as the basis that represents the current real world condition and establish the relevant CTS criteria. This intuitive alignment between the two methodologies encourages the integration of six sigma methodology when generating new enterprise models. As the enterprise model is measured and analysed, six sigma methodology continues to refine CTS that will ultimately changes the concept and requirements of the enterprise with a context shift of who the customer is. Thus, as the context or view changes, this will enable the creation of, or improvement of, processes resulting in the "TO BE" enterprise model.

The added benefit of using six sigma is that a set of controls can be established for the process and the enterprise which should be included in the enterprise model. With dynamic market demands, the critical to quality characteristics of today would not necessarily be meaningful tomorrow. All CTSs should be critically examined at all times and refined as necessary. For this 


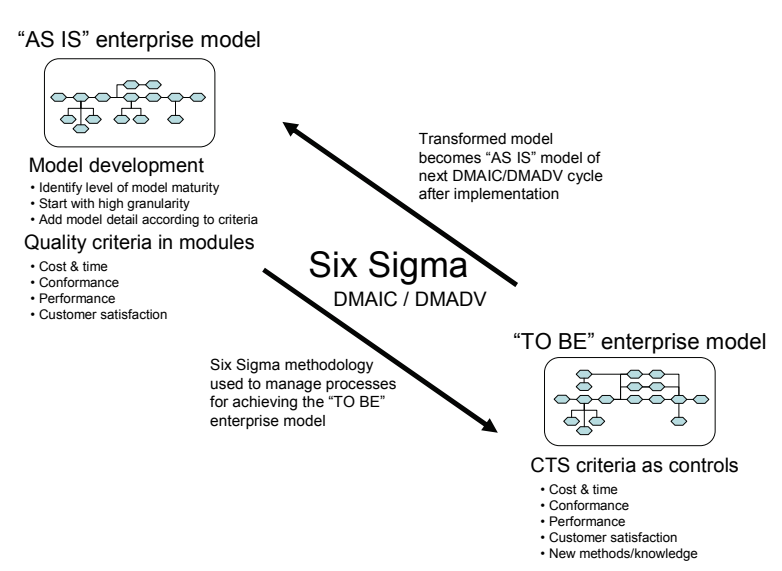

Fig. 6. Transition plan with six sigma

reason, a control plan developed from the last stage of the six sigma project should provide measures that indicate the performance and continued relevance of the processes within the transformed enterprise model. This can be an effective way of maintaining the enterprise model and relevance of the business to changing conditions.

\section{Progressive enterprise transformation process}

The issue of enterprise transformation is the uncertainty of future enterprise models, in other words, $\mathrm{M}_{n}$ may not be fully described! This means the roadmap for transformation from $\mathrm{M}_{1}$ to $\mathrm{M}_{n}$ may not be defined until very late in the project causing significant disruption of the transformation process and turbulence in the enterprise. Change from $\mathrm{M}_{1}$ to $\mathrm{M}_{n}$ is normally significant due to the fact that an organisation will normally seek advice from a wide variety of resources to achieve the new design. This change is too abrupt and will impose significant organisational turmoil and reduce the ability of the enterprise to compete against other organisations. Six sigma process has the advantage of self adjusting the system to suit the need of changes. The question is how to integrate six sigma tools as the method to make changes that are more than just continuous optimisation of a process. Linking six sigma with Enterprise Modelling to transform current state "AS IS" enterprise models to future state "TO BE" enterprise models with a clear road map is required.

If we follow the six sigma methodology, we will focus the transformation on process elements that have measurable CTS indicators relevant to internal business and external customer requirements. Therefore, as discussed in Figure 6, the CTSs form the foundation for decision making when redesigning or improving the process. The same indicators may form the controls to ensure continued performance of the new process or as indicators of when the new process is no longer relevant. Six sigma projects close the transformation loop by mapping CTS driven design requirements of the revised enterprise model.

Six sigma produces data driven solutions with relevant new and/or improved processes for the next "TO BE" enterprise model. It is therefore imperative that the initial "As Is" Enterprise Model contains accurate and relevant CTS information. It may be necessary to redefine the "AS IS" enterprise model to ensure that the CTS indicators and measurables are included and that the enterprise model does in fact represent the real life situation. This is in essence the first step (Define) of the six sigma project. The decision for any redesign efforts over traditional continuous improvement depends on a number of variables including risk, available technology \& resources, cost, customer demand, time and complexity etc. This is part of the six sigma methodology and covered in the "Define" stage present in both DMAIC and DMADV based projects.

Instead of having an abrupt change between two major enterprise models, the new transition methodology divides the gap into many manageable steps (Figure 5). The intermediate "TO BE" enterprise models $\mathrm{M}_{i}(1<i<n)$ in these steps are developed through six sigma projects. The changes are simple enough to be redefined. However, our emphasis is to make the change as smooth and manageable as possible to minimise impact. However, the future model $\mathrm{M}_{n}$ is defined to ensure a consistent approach or direction that governs each intermediate state to be processed by six sigma projects or a combinations of many grouped projects.

The road map developed for Enterprise Model transformation can be context related. The detail of each progressive enterprise model on the roadmap of enterprise transformation to $\mathrm{M}_{n}$ can be derived from six sigma projects with emphasis on the appropriate $\mathrm{M}_{i}$ design goals towards the ultimate state. This six sigma driven transformation becomes an iterative and progressive process of making changes leading to the larger enterprise model transformation in a similar manner to climbing Mount Everest. As the summit is ascended one step at a time, a new intermediate enterprise model may be developed until the summit can be reached in a final project. This progressive method of transformation is a logical approach for the enterprise model development that could become culturally more ingrained within the organisation already embracing six

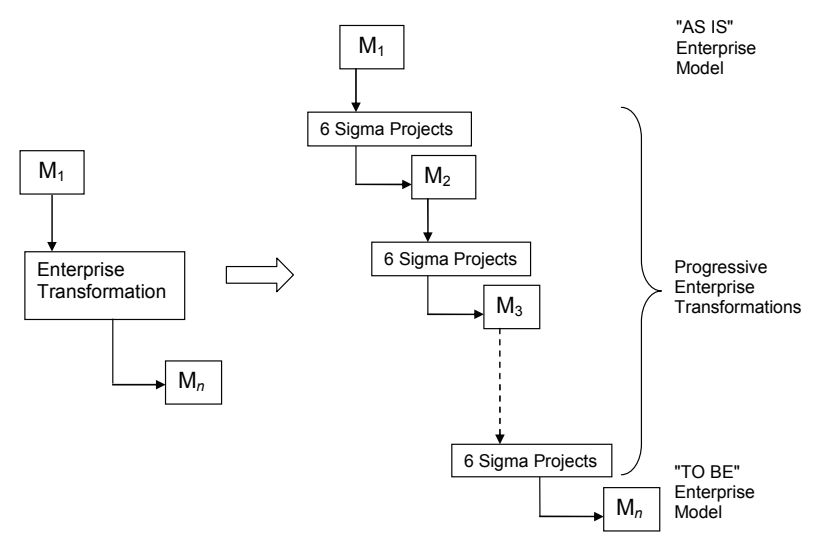

Fig. 5. Enterprise model transformations with progressive six sigma driven changes 
sigma for need based ongoing Enterprise Model Transformation (EMT).

In a more generic perspective, combining enterprise modelling with six sigma provides many benefits. Six sigma projects benefit from a big picture of the process lifecycle with the respective views or contexts. Enterprise modelling gains a tool set with methodology for transforming an "AS IS" enterprise model to the "TO BE" state. Within any stage of the lifecycle, the proposed alignment of the six sigma methodology to the generic enterprise architecture views remains the same. The changes from $\mathrm{M}_{i}$ to $\mathrm{M}_{i+1}$ is by methodological design to be incremental and manageable. The same tools and methods remain applicable during each of the steps used in transforming the different views of the enterprise model. The enterprise does not expect surprising disruption in this process and hence can progress smoothly through the enterprise model transformation.

\section{Case Study: Engineering approval process change}

We illustrate our proposed progressive enterprise model transformation approach by a case study at Ford Australia Pty Ltd. A process re-engineering project is presented here illustrating the use of six sigma as the tool to implement a needs based enterprise model transformation. The need for enterprise change was initiated by the long time required to approve engineering changes within the Product Development Organisation. From operational point of view, this change was driven by internal customer expectations. The case scenario is described below.

A new vehicle product development engineering service provided by Ford of Australia (FoA) to Ford India Private Limited (FIPL) required that an engineering change management process be extended to include approvals from FIPL. The initial implementation of the change management process was slow, cumbersome and did not meeting the needs of the business.

The change management activity was mapped including processes and organizational structure. A manifestation model of the present "AS IS" (M1) state was produced for that section of the organization. The requirements critical to customer satisfaction were identified and stated as a problem definition - completing the first stage of the six sigma methodology (Define). The "AS IS" enterprise model was found to be a linear process with static work flow. It was not obvious what the process issues were or what departments produced the delays. Issues seemed to be regular in occurrence, but unique in nature. An "AS IS" model of the implementation phase was available, however, accuracy was uncertain and there were no clear measures or controls to identify process deficiencies or where changes may be required.

The desirable future enterprise model $\left(\mathrm{M}_{n}\right)$ would have many of the processes running in parallel and the ability to assure clear track and trace of work items in the system. There was also expectations of reduction of costs in the new model.

Following six sigma methodology, key process and resource elements identified in the updated manifestation Enterprise Model were used to develop suitable measurable metrics that would reflect the process performance. These metrics focused on critical to satisfaction outcomes that included activities contributing to the delay of engineering change approvals. The metrics allowed key elements of the process to be measured and areas of deficiency to be identified.

During the Measure phase of the six sigma methodology, it was clear that not all the metrics were readily available. Key performance measures could not be effectively measured with the current manifestation of the Enterprise. This was the driver for the first level of transformation, the use of a change management and approvals database. The database would automatically report the performance metrics against agreed departmental targets. This paved the way for the development of a road map that would define the next phase of Enterprise Model transformation with a new Operational Enterprise Model.

The initial minor transformation with the database provided metrics data that was analysed after one month using six sigma statistical methods. It became clear how the new present model of this engineering activity was functioning and where the delays originated. The model identified a serial process flow. Performance metrics for each stage of the model were added presenting a clear view of what was happening in the enterprise.

Certain model activities were not necessary. Some activities were independent and were realigned as parallel activities. A new "TO BE" model $\left(\mathrm{M}_{2}\right)$ was created with multiple parallel activities. Some new tools were introduced and data from different activities were integrated within the newly established change management database. In this case, poor change management performance was the deficiency. The transformation did not reduce variability. It changed the operational definition and introduced integrated tools to address values from the perspective of the customer. The Enterprise Model Transformation that has gone through Ford Australia is illustrated in Figure 7.

The six sigma methodology provided the framework to define the problem and apply the standard tools to identify metrics that would measure the existing "AS IS" performance. Interim progressive change was identified and actioned to help make the transition to the final model $\left(\mathrm{M}_{2}\right)$. The final Enterprise Model $\left(\mathrm{M}_{2}\right)$ would address areas requiring transformation to correct the operational deficiency. Appropriate metrics and data were used to make decisions on where to transform the business when the extent of the transformation was not clear. The metrics to measure and sustain the improvements were built into the new "TO BE" model. 


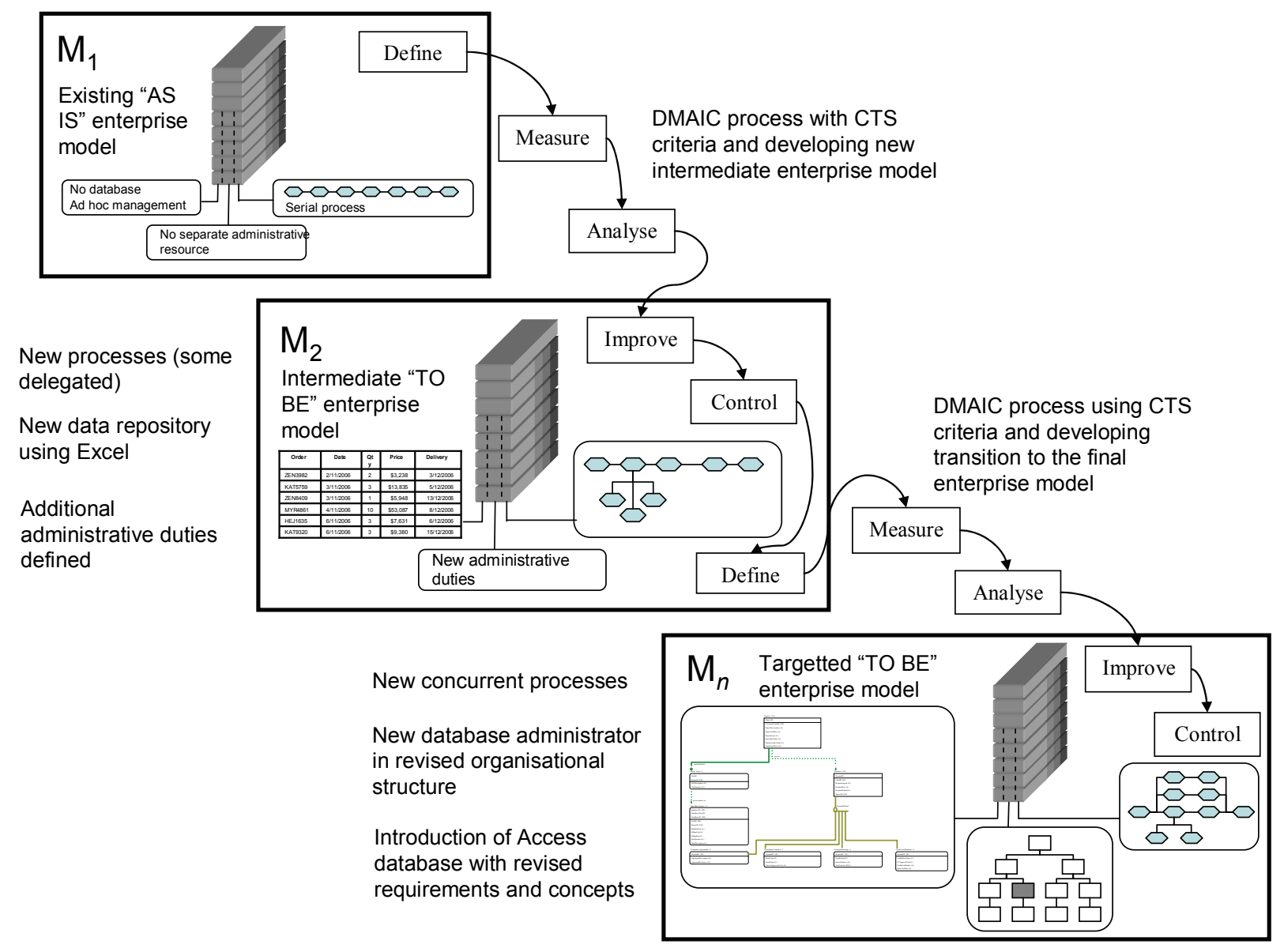

Fig. 7. Engineering approval process enterprise model transformation

\section{Conclusion}

If we accept that an enterprise needs to adapt and transform its processes to meet changing output deliverables and customer expectation within an increasingly competitive global environment, we must then have a plan or method by which we could transform the enterprise. Enterprise modelling alone is not sufficient in instigating this transformation. This paper has illustrated the importance of a new progressive enterprise transformation process supported by established enterprise modelling and six sigma methodologies.

The new six sigma driven enterprise transformation process is developed first with a description of an alignment of six sigma with the reference views in generic enterprise architecture and an outline of the framework that encourages the combined benefits of enterprise modelling and six sigma. This generalised framework provides the roadmap for enterprise transformation with readily accepted six sigma tools.

Six sigma focuses on the scope down to incremental improvement projects. Enterprise transformation based on enterprise modelling approach provides a visionary target for the business process engineer to work on. When combining the two methodologies, we can establish the total enterprise picture with the "TO BE" future state, complete with road map and six sigma tools to transform the enterprise can be established.

This proposed approach has been illustrated by a case study. This is an example of how six sigma methodology can be aligned with enterprise modelling to make effective, significant and progressive enterprise transformations. The "TO BE" enterprise model, together with a set of quality criteria as controls, becomes the new operational "AS IS" enterprise model and in the Everest analogy, forms one of the many steps to reaching the summit of enterprise model transformation. Further work is required to detail and standardize the processes of creating effective links between enterprise modelling and six sigma in a unified framework. The six sigma driven enterprise model transformation is a progressive enterprise change process and has proven to induce least disruption to business. It is a less risky approach for enterprise model transformation and improvement.

\section{References}

Beasley, M.S., Clune, R., Hermanson, D.R. (2005). Enterprise risk management: An empirical analysis of factors associated with the extent of implementation. Journal of Accounting and Public Policy, 24, 521-531

Buhman, C., Kekre, S., Singhal, J. (2005). Interdisciplinary and interorganizational research: establishing the 
science of enterprise networks. Production and Operations Management, 14(4), 493-514

Chen, D., Doumeingts, G., Vernadat, F. (2008). Architectures for enterprise integration and interoperability- Past, present and future. Computers in Industry, Vol.59, Iss.7, Sept, pp.647-659

Corbett L. M. (2008). Manufacturing strategy, the business environment, and operations performance in small low tech firms. International Journal of Production Research. pub. Taylor and Francis. Vol.46, Iss.20, pp.5491-5513

Dewhurst, F.W., Barber, K.D., Pritchard, M.C. (2002). In search of a general enterprise model. Management Decision, 40(5), 418-427

Goel S., Chen, V. (2008). Integrating the global enterprise using six sigma: Business process reengineering at General Electric Wind Energy. International Journal of Production Economics, Volume 113, Issue 2, June, pp.914-927

Goh, T.N. (2002). A strategic assessment of six sigma. Quality and Reliability Engineering International, Vol. 18 No.5, pp.403-410.

Jiju, A. (2004). Six sigma in the UK Service Organizations: results from a pilot survey. Managerial Auditing Journal, Vol.19, No.8, pp.1006-1013

Jochem, R. (2006). Enterprise Engineering Method supporting six sigma Approach. Proceedings of the 11th World Congress on Total Quality Management, 4-6 December, Wellington, NZ

Kutsch E., Hall M., Intervening conditions on the management of project risk: Dealing with uncentainty in information technology projects, International Journal of Project Management, 23, 2005, 591-599

Kwon, D., Oh, W., Jeon, S. (2007). Broken ties: The impact of organizational restructuring on the stability of information-processing networks, Journal of Management Information Systems, 24(1):201-231

Lin, C.Y.Y., Wei, Y.C. (2006). The role of business ethics in merger and acquisition success: An empirical study, Journal of Business Ethics, 69(1):95-109

Love, D., Barton, J. (1996). Evaluation of design decisions through CIM and simulation. Integrated Manufacturing Systems, 7(4), 3-11

Marino, A.M., Zabojnik, J. (2006). Merger, ease of entry and entry deterrence in a dynamic model, Journal of Industrial Economics, 54(3):397-423

McGinnis, L. F. (2007). Enterprise modeling and Enterprise Transformation. Information knowledge Systems Management 6(1/2), 123-143

Mo J.P.T., Zhou M., Anticev J., Nemes L., Jones M., Hall W. (2006). A study on the logistics and performance of a real 'virtual enterprise. International Journal of Business Performance Management, 8(2-3):152-169
Molina, A., Medina, V. (2003). Application of enterprise models and simulation tools for the evaluation of the impact of best manufacturing practices implementation. Annual Reviews in Control, 27:221228

Oberg, C., Henneberg, S. C., Mouzas, S. (2007). Changing network pictures: Evidence from mergers and acquisitions. Industrial Marketing Management, 36(7):926-940

Ortiz, A., Lario, F., Ros, L. (1999). Enterprise IntegrationBusiness Processes Integrated Management: a proposal for a methodology to develop Enterprise Integration Programs. Computers in Industry, Vol.40, pp.155, 171

Rho B. H., Park K., Yu Y. M. (2001). An international comparison of the effect of manufacturing strategyimplementation gap on business performance. International Journal of Production Economics, Vol.70, pp.89-97

Rouse, W. B. (2005a). A Theory of Enterprise Transformation. Systems Engineering. Wiley InterScience, Vol.8, Iss.4, pp.279-295

Rouse, W.B. (2005b). Enterprises as systems: Essential challenges and enterprise transformation, Systems Engineering, Vol.8, Iss.2, pp.138-150

Smith, H., Fingar, P. (2003). Digital six sigma Integrating continuous improvement, with continuous change, with continuous learning. BPTrends, Pub. Boston University Corporate Education Centre, http://www.bptrends.com, December

Smith, L.R., (2001). Six sigma and the Evolution of Quality in Product Development. Six Sigma Forum Magazine, Vol.1, No.1, pp.28-35

Török, J. (2004). 1-2-3 Model for Successful Six Sigma Project Selection. Pub. iSixSigma.com. First pub. 20 April 2005. Retrieved December 27, 2008, from http://europe.isixsigma.com/library/content/c050420b. asp

Uppington, G., Bernus, P. (2003). Analysing the Present Situation and Refining Strategy. In "Handbook on Enterprise Architecture", Ed. Bernus, P., Nemes, L., Schmidt, G. pub. Springer-Verlag, ISBN 3-540-003436, pp.309-332

Williams T.J., Bernus P., Brosvic J., Chen D., Doumeingts G., Nemes L., Nevins J.L., Vallespir B., Vlietstra J., Zoetekouw D. (1994). Architectures for integration manufacturing activities and enterprises. Computers in Industry, 24:111-139

Yin, X.L., Shanley, M. (2008). Industry determinants of the "merger versus alliance" decision. Academy of Management Review, 33(2):473-491 